\title{
Cisplatin-based Chemotherapy and Cardiac Functions Sub-acute Changes
}

\author{
Enas A. Elkhouly', Naglaa Faheem², Tarek M. Rageh ${ }^{3}$ \\ ${ }^{1}$ Department of Clinical Oncology and Nuclear Medicine, ${ }^{2}$ Cardiology Department, ${ }^{3}$ General \\ Surgery Department; Faculty of Medicine, Menoufia University, Egypt
}

Introduction: In earlier studies, investigating cardiac morbidity in long-term testicular cancer survivors 7-14 years after cisplatin-based chemotherapy, it was found that diastolic dysfunction present in around quarter of patients. In addition, subclinical signs of early vascular toxicity were found after cisplatin-based chemotherapy. However, little is known about the subacute cardiotoxicity in patients who received cisplatinbased chemotherapy. The aim of the current study was to investigate the echocardiographic changes before and one year after the start of cisplatin-based chemotherapy.

Patients and Methods: This was a prospective study that included twenty-six patients with locally advanced head and neck cancer, scheduled to receive induction cisplatin-based chemotherapy. Cisplatin-induced subacute cardiovascular toxicity was investigated. Echocardiographic cardiac assessments were done within 1 week before the start of chemotherapy and one year after the completion of treatment.

Results: Between January 2011 and December 2013, twenty six patients treated with cisplatin-based induction chemotherapy were included in our study with a median age of 53 years. Nasopharyngeal carcinoma represented $57.7 \%$ of the patients and $42.3 \%$ were hypo-pharyngeal carcinoma. Cardiovascular risk factors (CRF) before the start of chemotherapy were: hypertension in $11.5 \%$, diabetes in $15.4 \%$, dyslipidemia in $11.5 \%$, smoking in $15.4 \%$ and obesity in $11.5 \%$. Comparing the changes in echocardiography before and after treatment, the median wall motion score index did not change one year after treatment. Mitral and tricuspid diastolic parameters showed significant changes after treatment including: E/A ratio increase $(P<0.0002)$, tissue velocity imaging of early diastole (TVI Et) decrease $(P<0.0001)$ and isovolumetric relaxation time (IVRT) prolongation $(P<0.0001)$. The mitral and tricuspid TVI systolic parameters were not significantly affected.

Conclusion: We observed significant changes in right and left E/A, TVI Et and IVRT one year after cisplatinbased treatment, indicating a deterioration of diastolic cardiac function. The prognostic significance of this disturbed diastolic function after chemotherapy for future cardiovascular morbidity is not clear, but it might eventually lead to overt cardiac morbidity. Further longitudinal research in survivors is needed to obtain more insight in subclinical changes in cardiac function.

Key words: Cancer, Cisplatin, Echocardiography, Cardiotoxicity

Corresponding Author: Enas Abou Bakr Elkhouly

E-mail: enasaboubaker6@hotmail.com

\section{INTRODUCTION}

In earlier studies, investigating cardiac morbidity in long-term testicular cancer (TC) survivors at a median of 7-14 years after cisplatin-based chemotherapy, it is found that diastolic dysfunction in $17-33 \%$ of patients ${ }^{1}$. Subclinical signs of vascular toxicity were found in one prospective study that included TC patients 10 weeks after cisplatin-based chemotherapy ${ }^{2}$. Still, little is known about subacute cardio-toxicity in patients receiving cisplatin-based chemotherapy, and to our knowledge, no studies reported on early cardiotoxicity. Furthermore, it is not established which parameters are useful in the early assessment of cardiac damage.
In addition to obtaining insight in the extent and timing of cardiac complications of cisplatin-based chemotherapy, evaluation of the parameters for early (subclinical) cardiac dysfunction may enable the identification of patients who are at risk for future cardiovascular events. Echocardiography is a convenient and frequently used method to assess cardiac function, enabling evaluation of both systolic and diastolic function parameters.

In this prospective study, we investigated echocardiographic changes before and at 1 year after 


Vol. 10 | No. 3-4 $2014 \quad$ Enas A. Elkhouly et al

the start of cisplatin-based chemotherapy for locally advanced head and neck cancers.

\section{PATIENTS AND METHODS}

\section{Patients}

This is a prospective study include patients with locally advanced Head and Neck cancer, scheduled to receive induction cisplatin-containing chemotherapy at Clinical Oncology department, Menoufia University between January 2011and December 2013. Twenty six patients with locally advanced Nasopharyngeal and hypopharyngeal cancers were included in this study to investigate cisplatin-based chemotherapy induced sub-acute cardiovascular toxicity. Echo-cardio-graphic cardiac assessments were done within 1 week before the start of chemotherapy and one year after the completion of treatment.

Exclusion criteria were pre-treatment history of cardiac disease, an age older than 55 years at the start of chemotherapy, non- responding patients to the induction chemotherapy. The study was approved by the local ethics committee and written informed consent was obtained from all participants.

Patients with locally advanced Nasopharyngeal carcinoma (T1 N13-, and T2-T4 any N) treated with induction chemotherapy then concomitant chemoradiotherapy. Patients with locally advanced Hypopharyngeal carcinoma (T1 N+, selected T2 N0, and T23any $\mathrm{N}$ ), treated with induction chemotherapy, and patients with primary site complete response or partial response referred for concomitant chemo-radiotherapy (CRT) and were included in this study for expected better clinical outcome than non responding patients (NCCN, 2013). Induction chemotherapy was three cycles of three weekly courses of cisplatin-based combination chemotherapy TPF (Docetaxel, Platinum, and 5 FU), followed by radiotherapy concomitant with weekly cisplatin.

\section{Echocardiography}

Echocardiography was carried out by a skilled technician at the same laboratory using conventional equipment (General Electrical VIVID 9system, Horton, with a $5 \mathrm{M} \mathrm{Hz}$ probe) and consisted of two-dimensional echocardiography, color-flow mapping and, since 2002, tissue velocity imaging (TVI). Left ventricular enddiastolic dimension (LVEDD, normal 36-54 mm), left ventricular end-systolic dimension (LVESD, normal 23$40 \mathrm{~mm}$ ), posterior and septal wall thickness (normal 7-11 $\mathrm{mm}$ ) were measured on M-mode recordings obtained in the standard left ventricular parasternal long-axis view. The parasternal, transverse and longitudinal dimensions of the left atrium were attained. For the analysis of systolic function, the left ventricle was divided into 16 segments. Each segment was visually scored between 1 and 4 (11/4normokinesia, 21/4hypokinesia, 31/4akinesia, $4 \frac{1}{4}$ dyskinesia). The wall motion score index (WMSI) was the mean score for all the analyzed segments. A WMSI of 1.00 was considered normal. Diastolic function measurements included the mitral \& tricuspid valve inflow velocities in early (E) and late (atrial; A) diastole, E/A-ratio and tissue velocity imaging of early diastole (TVI Et) and late atrial diastole. Tissue velocity imaging of early diastole was the mean of measurements at the septal, lateral, inferior and anterior mitral annulus, also IVRT (isovolumetric relaxation time) was measured, and in addition mitral \& tricuspid annulus systolic parameters were measured by TVI.

\section{Cardiovascular risk factors (CRFs)}

Cardiovascular risk factors were estimated before the start of chemotherapy. Hyper-cholesterolaemia was defined as a fasting level of cholesterol greater than 200 $\mathrm{mg} / \mathrm{dl}$, diabetes mellitus as a fasting level of glucose greater than $110 \mathrm{mg} / \mathrm{dl}$. Obesity as a body mass index $(\mathrm{BMI}) \geq 25 \mathrm{~kg} / \mathrm{m} 2$. Blood pressure (BP) was estimated as a single recording on one arm in supine position in a quiet room after a minimal rest period of $10 \mathrm{~min}$. The criteria for hypertension were BP >14090/ and/or the use of anti-hypertensive medication.

\section{Statistics}

Statistical analyses were carried out using the statistical software package SPSS for Windows version 16.0 (SPSS Inc., Chicago, IL, USA). For comparisons the $\mathrm{x}^{2}$ test and the non-parametric Mann- Whitney test were used. To calculate changes within a patient the Wilcoxon signed-rank test was used on the paired samples in those patients where both variables were available. Regressions were calculated with Spearman's correlation. P-value less than 0.05 were considered to indicate significant differences.

\section{RESULTS}

Between January 2011 and December 2013, twentysix locally advanced head and neck cancer patients treated with cisplatin-based chemotherapy were enrolled in our study. Their median age was 53 years (range: $4355-$ ) and $58 \%$ of them had nasopharyngeal carcinoma and $42 \%$ had hypopharyngeal carcinoma. Cardiovascular risk factors (CRF) were estimated before the start of chemotherapy and they were: hypertension in $11.5 \%$, diabetes in $15.4 \%$, dyslipidemia in $11.5 \%$, smoking in $15.4 \%$ and obesity in $11.5 \%$ (Table 1). 
The conventional echocardiographic parameters before and after chemotherapy are shown in table 2. TVI echocardiographic parameters of mitral and tricuspid vlaves before and after chemotherapy are shown in tables 3 and 4 respectively.

Figure 1 illustrates conventional and TVI echocardiographic data before and after cispaltin-based chemotherapy.

In figure 2, pulsed wave doppler tissue imaging (DTI) after treatment shows negative deflect velocity recorded at the tricuspid annulus. In figure 3, pulsed wave DTI of the mitral annulus at the lateral border after treatment.

Echocardiography before cisplatin- based chemotherapy showed that two out of 26 patients had a WMSI (7.6\%). Mitral E/A-ratio was 0.91土 0.26. Tricuspid E/A ratio was $0.94 \pm 0.33$. TVI Et of mitral was $12.26 \pm 1.79 \mathrm{~cm} / \mathrm{sec}$, TVI Et for tricuspid was 14.23 $\pm 5.12 \mathrm{~cm} / \mathrm{sec}$. Mitral IVRT was $76.98 \pm 16.24 \mathrm{ml} / \mathrm{second}$ ; Tricuspid IVRT was $70.46 \pm 17.09 \mathrm{ml} / \mathrm{secod}$,. Mitral $\mathrm{S}$ wave was $11.681 .4 \pm \mathrm{cm} / \mathrm{sec}$, Mitral CT was 179.06 $\pm 20.45 \mathrm{ml} /$ second, Mitral PCT was $78.0816 .72 \pm \mathrm{ml} /$ second, Tricuspid S was $13.35+-1.62 \mathrm{~cm} / \mathrm{sec}$, Tricuspid PCT was $82.08 \pm 15.58 \mathrm{ml} /$ second and Tricuspid CT was

\section{$201.23 \pm 14.49 \mathrm{ml} /$ second.}

Echocardiography at a median of one year after the completion of cisplatin- based chemotherapy showed that two out of 26 patients had a WMSI $(7.6 \%)$, mitral $\mathrm{E} / \mathrm{A}$ ratio was $0.65 \pm 0.11$,tricuspid $\mathrm{E} / \mathrm{A}$ ratio was $0.62 \pm 0.11$, mitral TVI Et was 10.95 $\pm 1.34 \mathrm{~cm} / \mathrm{sec}$, tricuspid TVI Et was $12.35 \pm 4.27 \mathrm{~cm} /$ sec, mitral IVRT was $116.7 \pm 15.04 \mathrm{ml} / \mathrm{second}$, tricuspid IVRT was $92.92 \pm 17.24 \mathrm{ml} /$ second, mitral $\mathrm{S}$ was $11.45 \pm 1.42 \mathrm{~cm} / \mathrm{sec}$, mitral $\mathrm{PCT}$ was 79.98 $+19.06 \mathrm{ml} / \mathrm{second}$, mitral CT was $182.35 \pm 21.1 \mathrm{ml} /$ second, tricuspid $\mathrm{S}$ was $13.08 \pm 15.2 \mathrm{~cm} / \mathrm{sec}$, tricuspid PCT was $84.92 \pm 9.88 \mathrm{ml} / \mathrm{second}$, tricuspid CT was $202.23 \pm 13.96 \mathrm{ml} / \mathrm{second}$.

Tissue velocity imaging (TVI) echocardiographic parameters before and after chemotherapy showed that the median WMSI did not change one year after treatment. Mitral and tricuspid diastolic parameters showed significant changes including: increase in the E/A ratio $(P<0.0002)$, decrease in the TVI Et $(P<0.0001)$ and prolongation of the IVRT $(P<0.0001)$. On the other hand, the mitral and tricuspid TVI systolic parameters (S, PCT, CT) were not significantly affected.

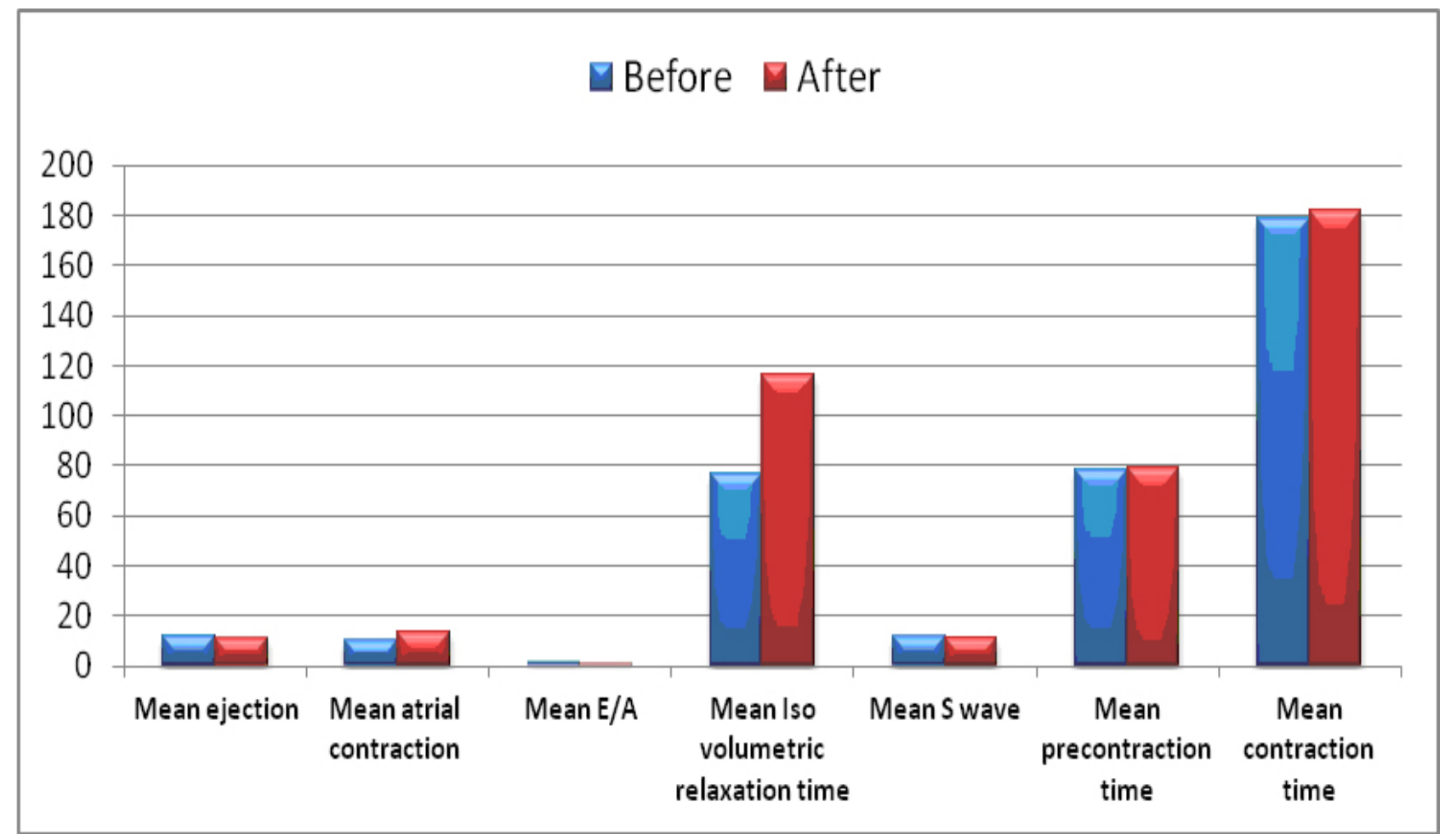

Figure 1: Conventional and tissue velocity imaging echocardiographic data before and after cispaltin-based chemotherapy. 


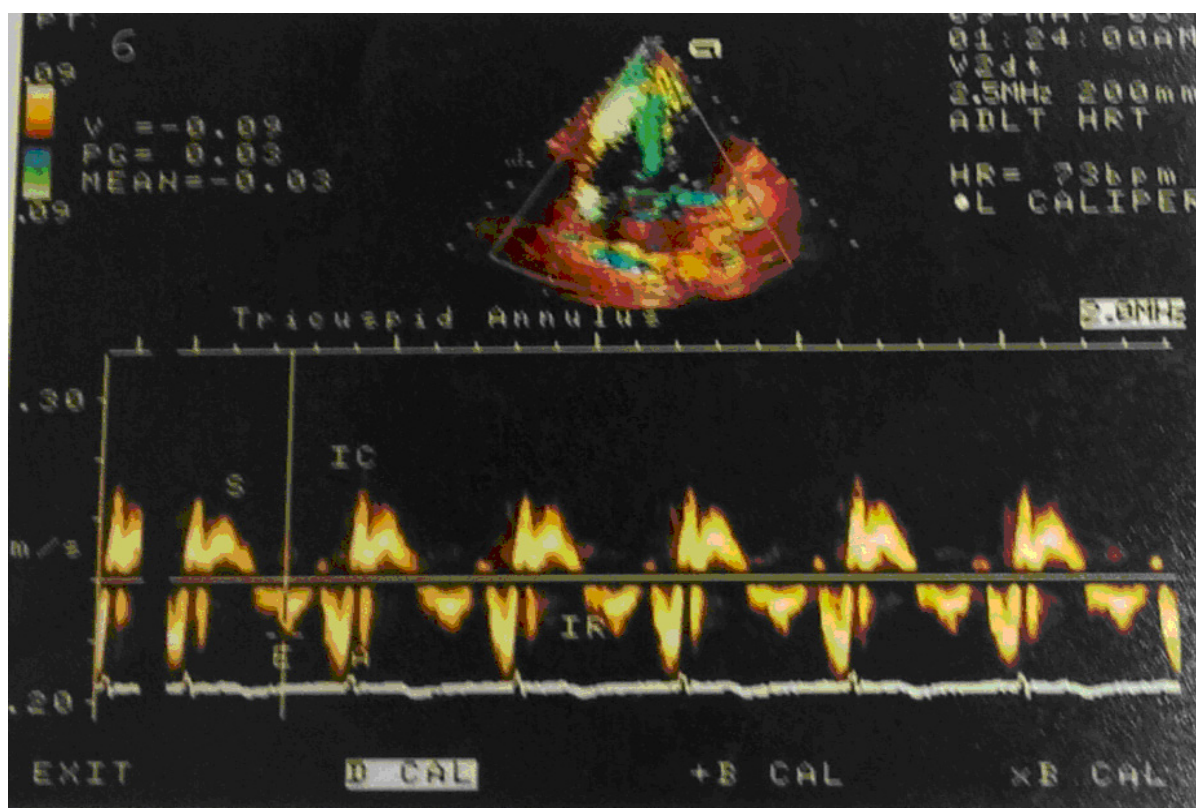

Figure 2: Pulsed wave Doppler tissue imaging (DTI) after treatment shows negative deflect velocity recorded at the tricuspid annulus.

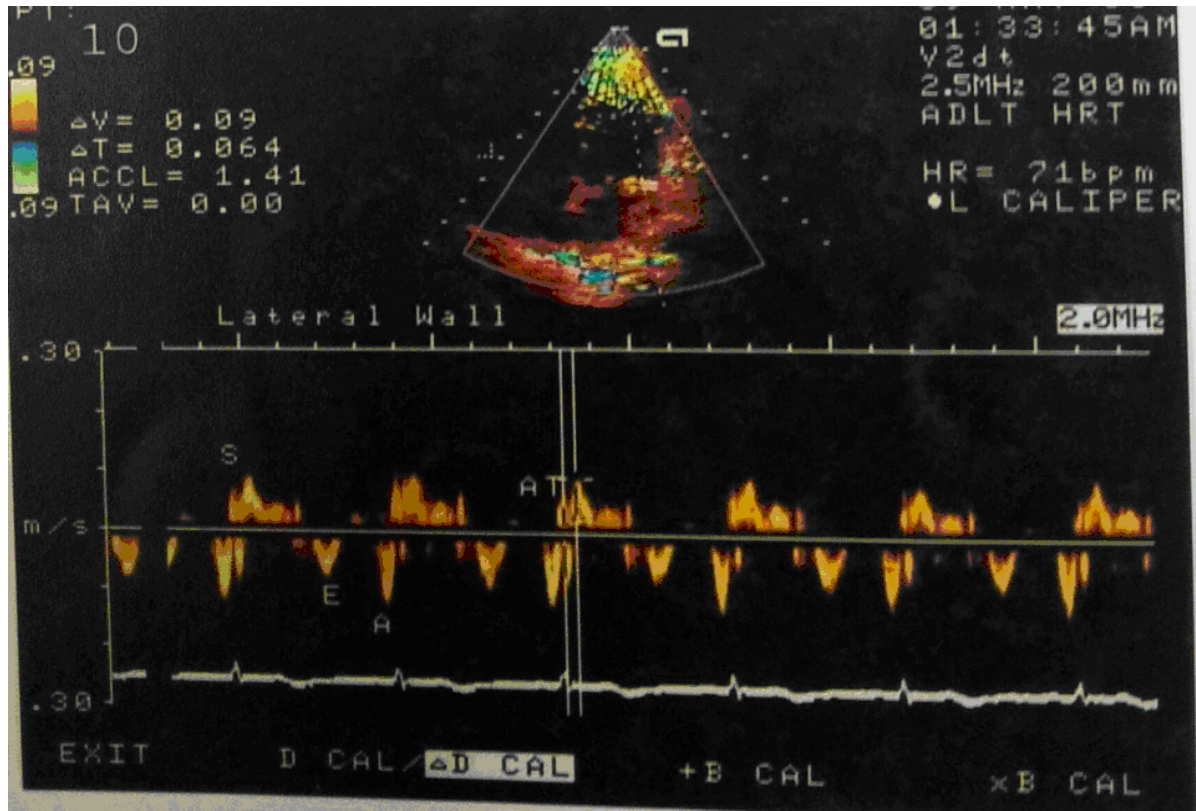

Figure 3: Pulsed wave DTI of the mitral annulus at the lateral border after treatment.

Table 1: Characteristics of participating patients.

The studied patients $(\mathrm{N}=\mathbf{2 6})$

\begin{tabular}{lcc}
\hline Age & \multicolumn{2}{c}{$50.85 \pm 4.46$} \\
Mean \pm SD & $53(43-57)$ & $\%$ \\
Median (range) & No & 100 \\
\hline Sex & & 26 \\
$\quad$ Male & 0 & 0.0 \\
$\quad$ Female & & \\
\hline
\end{tabular}




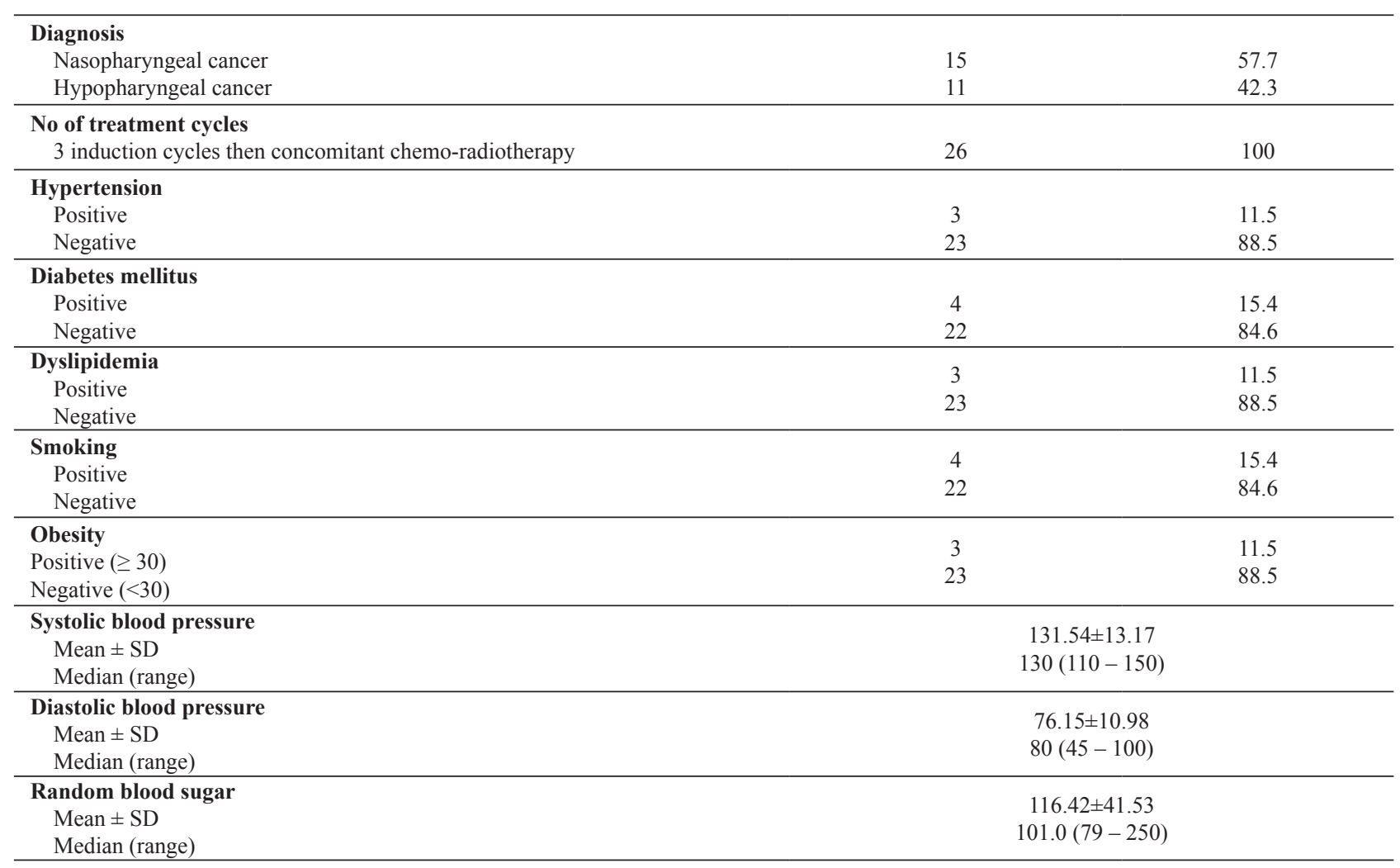

Table 2: Conventional echocardiographic parameters before and after chemotherapy in 26 patients.

\begin{tabular}{lcccc}
\hline & Before chemotherapy & After chemotherapy & \multirow{2}{*}{ Paired t } & \multirow{2}{*}{ P value } \\
\cline { 2 - 4 } IVS & mean \pm SD & mean \pm SD & $9.58 \pm 1.63$ & 0.0 \\
\hline PW & $9.58 \pm 1.63$ & $9.54 \pm 1.63$ & 0.0 & 1.0 \\
\hline LVED & $9.54 \pm 1.63$ & $49.08 \pm 6.32$ & 0.91 & 0.37 \\
\hline LVSD & $48.23 \pm 6.08$ & $32.23 \pm 5.40$ & 1.22 & 0.23 \\
\hline LA & $31.04 \pm 4.26$ & $34.81 \pm 4.52$ & 3.29 & 0.003 \\
\hline Aorta & $35.81 \pm 4.29$ & $31.54 \pm 2.21$ & 2.31 & 0.03 \\
\hline RV & $32.04 \pm 2.39$ & $13.42 \pm 1.06$ & 0.37 & 0.71 \\
\hline FS & $13.38 \pm 1.13$ & $33.58 \pm 5.20$ & 2.02 & 0.05 \\
\hline EF & $35.42 \pm 4.24$ & $62.15 \pm 7.21$ & 1.78 & 0.09 \\
\hline Wall motion segmental score & $64.54 \pm 5.40$ & $1.08 \pm 0.27$ & 0.0 & 1.0 \\
\hline Mitral flow ejection & $1.08 \pm 0.27$ & $48.54 \pm 13.84$ & 2.97 & 0.006 \\
\hline Mitral flow E/A & $57.77 \pm 17.56$ & $0.65 \pm 0.11$ & 3.55 & 0.002 \\
\hline Mitral flow atrial contraction & $0.91 \pm 0.26$ & $72.65 \pm 12.61$ & 5.47 & $<0.001$ \\
\hline Tricuspid flow ejection & $64.73 \pm 13.38$ & $32.85 \pm 10.77$ & $4.38^{*}$ & $<0.001$ \\
\hline Tricuspid flow atrial contraction & $39.0 \pm 13.99$ & $52.54 \pm 11.05$ & $4.47^{*}$ & $<0.001$ \\
\hline Tricuspid flow E/A & $43.81 \pm 14.82$ & $0.62 \pm 0.11$ & $4.46^{*}$ & $<0.001$ \\
\hline *Wilcoxon Signed Rank & $0.94 \pm 0.33$ & &
\end{tabular}

Table 3: Tissue velocity imaging (TVI) echocardiographic parameters of mitral annuli before and after chemotherapy in 26 patients.

\begin{tabular}{lccccc}
\hline & Before chemotherapy & After chemotherapy & \multirow{2}{*}{ Paired t } & \multirow{2}{*}{ P value } \\
\cline { 2 - 3 } Mean ejection & mean \pm SD & mean \pm SD & & & \\
\hline Mean atrial contraction & $12.26 \pm 1.79$ & $10.95 \pm 1.34$ & 7.41 & $<0.001$ \\
\hline Mean E/A & $10.07 \pm 1.47$ & $13.85 \pm 1.51$ & 23.99 & $<0.001$ \\
\hline Mean Iso volumetric relaxation time(IVRT) & $1.26 \pm 0.16$ & $0.80 \pm 0.08$ & 18.66 & $<0.001$ \\
\hline Mean S wave & $76.98 \pm 16.24$ & $116.70 \pm 15.04$ & 11.79 & $<0.001$ \\
\hline Mean precontraction time(PCT) & $11.68 \pm 1.40$ & $11.45 \pm 1.42$ & 2.63 & 0.01 \\
\hline Mean contraction time(CT) & $78.08 \pm 16.72$ & $79.48 \pm 19.06$ & 1.43 & 0.17 \\
\hline
\end{tabular}


Kasr-El-Aini Journal Of Clinical Oncology And Nuclear Medicine

Vol. 10 | No. 3-4 $2014 \quad$ Enas A. Elkhouly et al

Table 4: Tissue velocity imaging (TVI) echocardiographic parameters of tricuspid valve before and after chemotherapy

\begin{tabular}{lccccc}
\hline & Before chemotherapy & After chemotherapy & \multirow{2}{*}{ Paired t } & \multirow{2}{*}{ P value } \\
\cline { 2 - 5 } Tricuspid ejection & mean \pm SD & mean \pm SD & & $4.23^{*}$ & $<0.001$ \\
\hline Tricuspid atrial contraction & $14.23 \pm 5.12$ & $12.35 \pm 4.27$ & $15.23 \pm 5.17$ & $4.23^{*}$ & $<0.001$ \\
\hline Tricuspid E/A & $12.27 \pm 4.65$ & $0.81 \pm 0.19$ & 8.12 & $<0.001$ \\
\hline Tricuspid isovolumetric relaxation time(IVRT) & $1.19 \pm 0.32$ & $92.92 \pm 17.24$ & 8.43 & $<0.001$ \\
\hline Tricuspid S wave & $70.46 \pm 17.09$ & $13.08 \pm 1.52$ & 3.03 & 0.006 \\
\hline Tricuspid precontraction time(PCT) & $13.35 \pm 1.62$ & $84.92 \pm 9.88$ & 1.46 & 0.16 \\
\hline Tricuspid contraction time(CT) & $82.08 \pm 15.58$ & $202.23 \pm 13.96$ & 1.79 & 0.09 \\
\hline
\end{tabular}

\section{DISCUSSION}

In this prospective study that included a group of head and neck patients who received cisplatinbased chemotherapy, there were observed changes in the mitral and tricuspid E/A, TVI Et and IVRT 1 year after chemotherapy administration, representing a deterioration in diastolic cardiac functions.

Meinardi et $\mathrm{al}^{3}$, Strumberg et $\mathrm{al}^{4}$, Huddart et $\mathrm{al}^{5}$ and van den Belt-Dusebout et $\mathrm{al}^{6}$ reported changes in cardiovascular status within years to decades after chemotherapeutic treatment for TC but little is known about the early changes in cardiac function in these patients.

Regarding treatment related cardiotoxicity from various cancer treatments, Ewer and Lenihan ${ }^{7}$ found that diastolic cardiac function deteriorates before the development of systolic dysfunction. In left ventricular dysfunction of various origins, Lester et $\mathrm{al}^{8}$ found that a deterioration of diastolic function can be present in the absence of systolic impairment, and Zile and Brutsaert ${ }^{9}$ found that subclinical diastolic dysfunction frequently precedes a drop in systolic parameters. Echocardiography is a frequently used method for assessing cardiac function, which has the advantage of enabling a reliable estimation of diastolic function by means of more recently introduced parameters, such as TVI Et and IVRT. Other diastolic parameters, like the E/A-ratio, are largely dependent on preload conditions, resulting in significant intra-individual variation as detected by Hurrell et $\mathrm{al}^{10}$ and Sohn et $\mathrm{al}^{11}$.

The TVI Et assesses the velocity of the myocardium at different angles from the mitral valve, instead of blood-flow velocities and is therefore independent of loading conditions ${ }^{11,12}$, resulting in less intra-individual variation. This parameter is considered an important and reliable early predictor for the development of cardiac dysfunction in other causes of cardiac disease. As found by Nikitin and Witte ${ }^{12}$, Kapusta et $\mathrm{al}^{13}$, Brouwer et $\mathrm{al}^{14}$ Tassan-Mangina et $\mathrm{ll}^{15}$ and Galderisi et $\mathrm{al}^{16}$ in their studies in adult childhood cancer survivors, it seemed to be a valuable parameter in defining diastolic dysfunction. TVI Et and the E velocity, thereby including the end-diastolic left ventricular filling pressure in addition to myocardial velocities. According to Paulus et $\mathrm{al}^{17}$, this parameter is currently regarded as a valuable non-invasive method for diagnosing diastolic heart failure. Declines in diastolic cardiac function are reflected by decreases in TVI Et, in addition to IVRT prolongation.

In this study we did not further investigate explanations for this cardiovascular toxicity. The main causes are thought to be related to direct damage to cardiomyocytes and/or the extracellular matrix, as well as subclinical vascular injury that induces endothelial dysfunction. Furthermore, the presence of pre-treatment elevations in BP may have resulted in impaired relaxation of the left ventricle, thereby leading to diastolic function decline.

It is unknown whether a deterioration of diastolic cardiac function during the first year after chemotherapy for patients will progress to clinically relevant cardiac disease.

\section{CONCLUSION}

In conclusion, we observed significant changes in right and left, E/A, TVI Et and IVRT within 1 year after cisplatin-based treatment, indicating a deterioration of diastolic cardiac function. The prognostic significance of this disturbed diastolic function after chemotherapy for future cardiovascular morbidity is not clear, but it might eventually lead to overt cardiac morbidity. Further longitudinal research in survivors is needed to obtain more insight in sub-clinical changes in cardiac function.

Disclosure: The authors have declared no conflicts of interest. 


\section{REFERENCES}

1. Nuver J, Smit AJ, Sleijfer DT, et al. Left ventricular and cardiac autonomic function in survivors of testicular cancer. Eur J Clin Invest. 2005;35: 99-103.

2. Nuver J, Smit AJ, van der MJ, et al. Acute chemotherapyinduced cardiovascular changes in patients with testicular cancer. J Clin Oncol. 2005;23: 9130- 9137

3. Meinardi MT, Gietema JA, van der Graaf WT, et al. Cardiovascular morbidity in long-term survivors of metastatic testicular cancer. J Clin Oncol. 2000;18: $1725-1732$.

4. Strumberg D, Brugge S, Korn MW, et al. Evaluation of long-term toxicity in patients after cisplatin-based chemotherapy for non-seminomatous testicular cancer. Ann Oncol. 2002;13:229-236.

5. Huddart RA, Norman A, Shahidi M, et al. Cardiovascular disease as a long-term complication of treatment for testicular cancer. J Clin Oncol. 2003;21: 1513-1523

6. van den Belt-Dusebout AW, deWR, Gietema JA, et al. Treatment-specific risks of second malignancies and cardiovascular disease in 5-year survivors of testicular cancer. J Clin Oncol. 2007;25:4370-4378

7. Ewer MS and Lenihan DJ.Left ventricular ejection fraction and cardio-toxicity: is our ear really to the ground? J Clin Oncol. 2008;26:1201-1203

8. Lester SJ, Tajik AJ, Nishimura RA, et al. Unlocking the mysteries of diastolic function: deciphering the Rosetta Stone 10 years later. J Am Coll Cardiol. 2008;51: 679689.

9. Zile MR and Brutsaert DL. New concepts in diastolic dysfunction and diastolic heart failure: Part I: diagnosis, prognosis, and measurements of diastolic function. Circulation. 2002;105:1387-1393

10. Hurrell DG, Nishimura RA, Ilstrup DM, et al. Utility of preload alteration in assessment of left ventricular filling pressure by Doppler echocardiography: a simultaneous catheterization and Doppler echocardiographic study. J Am Coll Cardiol. 1997;30: 459- 467.
11. Sohn DW, Chai IH, Lee DJ, et al. Assessment of mitral annulus velocity by Doppler tissue imaging in the evaluation of left ventricular diastolic function. J Am Coll Cardiol. 1997;30:474-480

12. Nikitin NP and Witte KKA. Application of Tissue Doppler Imaging in cardiology. Cardiology. 2004;101:170-184

13. Kapusta L, Thijssen JM, Groot-Loonen J, et al. Discriminative ability of conventional echocardiography and tissue Doppler imaging techniques for the detection of subclinical cardiotoxic effects of treatment with anthracyclines. Ultrasound Med Biol. 2001;27:16051614

14. Brouwer CA, Gietema JA, van den Berg MP, et al. Longterm cardiac follow-up in survivors of a malignant bone tumour. Ann Oncol. 2006;17:1586-1591.

15. Tassan-Mangina S, Codorean D, Metivier M, et al. Tissue Doppler imaging and conventional echocardiography after anthracycline treatment in adults: early and late alterations of left ventricular function during a prospective study. Eur J Echocardiogr. 2006;7:141-146

16. Galderisi M, Marra F, Esposito R, et al. Cancer therapy and cardiotoxicity: the need of serial Doppler echocardiography. Cardiovasc Ultrasound. 2007;5:4.

17. Paulus WJ, Tscho"pe C, Sanderson JE, et al. How to diagnose diastolic heart failure: a consensus statement on the diagnosis of heart failure with normal left ventricular ejection fraction by the Heart Failure and Echocardiography Associations of the European Society of Cardiology. Eur Heart J. 2007;28:2539-2550

18. Nuver J, Smit AJ, Wolffenbuttel BH, et al. The metabolic syndrome and disturbances in hormone levels in longterm survivors of disseminated testicular cancer. J Clin Oncol. 2005;23:3718-3725. 